\section{Proteine, globuläre}

\section{H. Fiedler}

Erfurt, Deutschland

Englischer Begriff globular proteins; spheroproteins

Definition Globuläre Proteine haben in gelöstem Zustand eine kugelähnliche Gestalt, meist sind es Rotationsellipsoide mit unterschiedlichen Achsenverhältnissen (meist $<4: 1$ ).

Beschreibung Die kompakte Faltung der globulären Proteine lässt im Inneren kaum Raum für Wassermoleküle. Die hydrophilen Gruppen sind nach außen (Löslichkeit in Wasser), die hydrophoben Gruppen zum Inneren gerichtet. Viele globuläre Moleküle sind leicht durch Temperatur- oder pH-Änderungen denaturierbar und verlieren dabei ihre biologische Aktivität und Löslichkeit. Durch Viskositätsmessungen ( $>$ Viskosimetrie) kann das Achsenverhältnis annähernd ermittelt werden. Die Methoden zur genauen Strukturanalyse sind unter $>$ Proteinstruktur beschrieben.
Die meisten für die Labordiagnostik benutzten Proteine gehören zu den globulären Proteinen: Plasmaproteine ( $\vee$ Protein, gesamt im Serum (Plasma)), Enzyme, Antikörper, Histone und sauerstoffübertragende Globine. Letztere haben als Kofaktor einen Eisen-Porphyrin-Komplex (Häm) und sind als Hämoglobin oder Myoglobin lange bekannt. 2002 wurde in fast allen Zellen ein Cytoglobin mit 190 Aminosäuren und Myoglobin-ähnlicher Struktur entdeckt. Im Nervengewebe und Gehirn war bereits 2000 ein ähnliches Neuroglobin gefunden worden. Obwohl noch nicht alle Funktionen geklärt wurden, bieten diese Globine neben der Sauerstoffübertragung und -speicherung auch Schutz vor oxidativem und nitrosativem Stress, Apoptose und Neurodegeneration.

\section{Literatur}

Oleksiewicz U, Liloglou T, Field JK, Xinarianos G (2011) Cytoglobin: biochemical, functional and clinical perspective of the newest member of the globin family. Cell Mol Life Sci 68:3869-3883

Xie LK, Yang SH (2016) Brain globins in physiology and pathology. Med Gas Res 6:154-163 